\title{
Avaliação do Caráter das Praças de Umuarama - PR
}

Character Evaluation of the Squares of Umuarama - PR

Evaluación del Carácter de las Plazas de Umuarama - PR

\section{Carolina Cardoso}

Mestranda, UEM, Brasil carolinac.arq@hotmail.com

\section{Yara Campos Miranda} Mestranda, UEM, Brasil yaracamposmiranda1@gmail.com

\section{Bruno Luiz Domingos De Angelis}

Professor, Doutor, UEM, Brasil brucagen@uol.com.br 


\section{RESUMO}

Os espaços livres estão enraizados na urbanização das cidades brasileiras desde o período colonial. O planejamento e o projeto de novas cidades impulsiona a criação de espaços livres, como no caso do município de Umuarama Paraná. A cidade, fundada no ano de 1955, possui um sistema viário radial, fundamentado no conceito de CidadeJardim, que utiliza malhas ortogonais e diagonais no traçado das vias. Este plano possibilitou a implantação de diversas praças, que fazem parte da história da cidade por estarem presentes desde a sua fundação, ainda que seja recente. O objetivo deste artigo é analisar os espaços livres da cidade de Umuarama - PR. Para isto, foi realizado um estudo de caso nas praças Santos Dumont, Arthur Thomas e Miguel Rossafa, localizadas em região central e previstas no projeto original da cidade. $\mathrm{O}$ método utilizado nesta pesquisa compreende a análise do caráter de praças históricas, proposto por Yamaki (2008). O método propõe dez critérios de análise que envolve a avaliação tanto da estrutura da praça, quanto da sua história. A síntese da análise é apresentada em forma de um gráfico radar. Os resultados mostram que a falta de significação histórica não prejudica a percepção geral do espaço livre.

PALAVRAS-CHAVE: Espaço livre. Áreas verdes. Cidades planejadas.

\section{ABSTRACT}

Planning and project of new cities promotes the creation of open spaces, as in the case of Umuarama-PR city. Its radial road system allowed the implantation of several squares, which are part of the city's history. The objective is to analyze the open spaces of the city of Umuarama - PR. For this, a case study was carried out in the Santos Dumont, Arthur Thomas and Miguel Rossafa squares, located in central region and foreseen in the city's original project. The method used, proposed by Yamaki (2008), comprises the analysis of the character of historical squares. The method proposes ten criteria of analysis that involves the evaluation of the structure of the square and its history. The synthesis of the analysis is presented in the form of a radar chart. The results show that the lack of historical significance does not detract from the general perception of free space.

KEY-WORDS: Open space. Green areas. Planned cities.

\section{RESUMEN}

Los espacios libres están arraigados en la urbanización de las ciudades brasileñas desde el período colonial. La planificación y el proyecto de nuevas ciudades impulsa la creación de espacios libres, como en el caso del municipio de Umuarama - Paraná. La ciudad, fundada en el año 1955, posee un sistema vial radial, fundamentado en el concepto de Ciudad-Jardín, que utiliza mallas ortogonal y diagonal en el trazado de las vías. Este plan posibilitó la implantación de diversas plazas, que forman parte de la historia de la ciudad por estar presentes desde su fundación, aunque sea reciente. El objetivo de este artículo es analizar los espacios libres de la ciudad de Umuarama - PR. Para ello, se realizó un estudio de caso en las plazas Santos Dumont, Arthur Thomas y Miguel Rossafa, ubicadas en región central y previstas en el proyecto original de la ciudad. El método utilizado en esta investigación comprende el análisis del carácter de plazas históricas, propuesto por Yamaki (2008). El método propone diez criterios de análisis que involucra la evaluación tanto de la estructura de la plaza, como de su historia. La síntesis del análisis se presenta en forma de un gráfico de radar. Los resultados muestran que la falta de significación histórica no perjudica la percepción general del espacio libre.

PALABRAS CLAVE: Espacio libre. Áreas verdes. Ciudades planeadas. 


\section{INTRODUÇÃO}

A paisagem urbana é composta pela estrutura dos seus espaços, livres e edificados, e suas inter-relações, a qual se dá o nome de morfologia urbana (HULSMEYER, 2004). Os espaços livres, em especial as ruas e as praças, são os elementos básicos que definem e delimitam a morfologia urbana (KRIER, 1979). Os espaços livres urbanos como conhecemos hoje passaram por transformações ao longo dos séculos, desde o seu aparecimento sutil nas cidades clássicas da Grécia e Roma, até a sua incorporação ao traçado urbano das cidades planejadas. A praça, uma das tipologias de espaços livres urbanos, está enraizada nas cidades brasileiras devido ao processo de formação das cidades coloniais. As primeiras vilas do país se originavam a partir da implantação da igreja e, consequentemente, do seu adro, que viria a se transformar na primeira praça da urbe (MARX, 1989). O aspecto simbólico da praça se manteve mesmo durante e depois do período pombalino, época na qual as cidades eram planejadas a partir da praça (CALDEIRA, 2007).

É comum que as cidades revitalizem seus espaços livres, em especial da praça, como forma de melhorar a qualidade de vida e resgatar as memórias da sociedade por meio de intervenções urbanas (CALDEIRA, 2007). Assim, é importante que o poder público esteja atento a estes espaços, requalificando-os quando necessário para atender aos anseios da população.

O objetivo deste artigo é analisar o caráter dos espaços livres de uma cidade nova, de fundação recente. Para isto, foi realizado um estudo de caso nas praças Santos Dumont, Arthur Thomas e Miguel Rossafa, localizadas na região central da cidade de Umuarama - Paraná, e presentes desde a fundação da cidade. O método utilizado para este estudo de caso consiste na análise do caráter de praças históricas, desenvolvido por Yamaki (2008).

\section{MÉTODO}

O método utilizado nesta pesquisa, desenvolvido por Yamaki (2008), consiste na análise do caráter de praças históricas a partir de dez critérios que resultam da síntese das características consideradas importantes para a construção da identidade de espaços públicos. Os critérios são identificados e detalhados a seguir:

I. Primeira Impressão: a primeira impressão que a praça causa no usuário deve considerar a legibilidade do espaço, o conjunto de características e elementos presentes na praça, tais quais as atividades realizadas no espaço, o estado de conservação e manutenção, e a aparência geral que inclui o traçado, a vegetação, o mobiliário e outras estruturas presentes na praça;

II. Relevo: este critério avalia a topografia como um elemento de impacto, que define a característica da praça;

III. Acessos e circulação interna: compreende a facilidade de acesso à praça - avalia a presença de obstáculos e o tráfego - e as alternativas de movimentação pela praça; 
IV. Vegetação: representado pelas características do paisagismo na praça, como as espécies plantadas, a organização da vegetação, o volume das plantas, porte das árvores, produção de sombra e presença de flores;

V. Mobiliário: o mobiliário é compreendido por bancos, lixeiras, luminárias, entre outros, e deve ser analisado como elemento estruturador do traçado da praça, que contribui para a sua identificação;

VI. Vistas: compreende as perspectivas visuais, seja a visibilidade da praça a partir de certa distância, ou as vistas e panoramas proporcionados em pontos estratégicos da praça. Inclui também o controle visual de toda a praça;

VII. Escala: a dimensão da praça em relação ao traçado urbano e às edificações do entorno; VIII. História e Significado da Praça: analisa a carga simbólica da praça, seu ano de fundação e os eventos realizados nela;

IX. História e Significado Visual do Entorno: edificações, caminhos e bairros do entorno da praça que possibilitam o reconhecimento visual;

X. Apropriação pela Comunidade: uso da praça pela comunidade por meio de atividades variadas - lazer, esportivas, descanso, entre outras - e sua periodicidade - diária, sazonais, eventuais.

Para cada um dos critérios foi atribuída uma nota de 1 a 3, composta pela identificação dos pontos positivos, neutros e negativos correspondentes a cada categoria de análise. As características percebidas como positivas receberam a maior nota (3 pontos), as consideradas neutras tiveram pontuação intermediária ( 2 pontos), e os elementos percebidos como negativos obtiveram a menor nota (1 ponto).

\section{MATERIAIS E ANÁLISE DE RESULTADOS}

A cidade de Umuarama foi fundada em 1955, apresenta mais de 100 mil habitantes (IBGE, 2010) e é sede da Região Metropolitana de Umuarama. A colonização da cidade foi impulsionada pela Companhia Melhoramentos Norte do Paraná (CMNP). O projeto urbano original, do ano de 1956, é de autoria do engenheiro geodésico Wladimir Babcov. Para a elaboração do projeto urbano, utilizou-se o conceito conhecido como cidade-jardim, difundido por Ebenezer Howard, caracterizado por um plano radial do sistema viário adaptado à topografia do local, incorporando malhas ortogonais e diagonais no traçado das vias. Este sistema possibilita a implantação de diversas praças, entre elas, os objetos de estudo: as praças Santos Dumont, Arthur Thomas e Miguel Rossafa. As três praças pertencem ao eixo viário da Avenida Paraná (Figura 1), uma das vias mais importantes da cidade. 
Figura 1: Eixo viário da Av. Paraná com indicação das praças Miguel Rossafa, Arthur Thomas e Santos Dumont

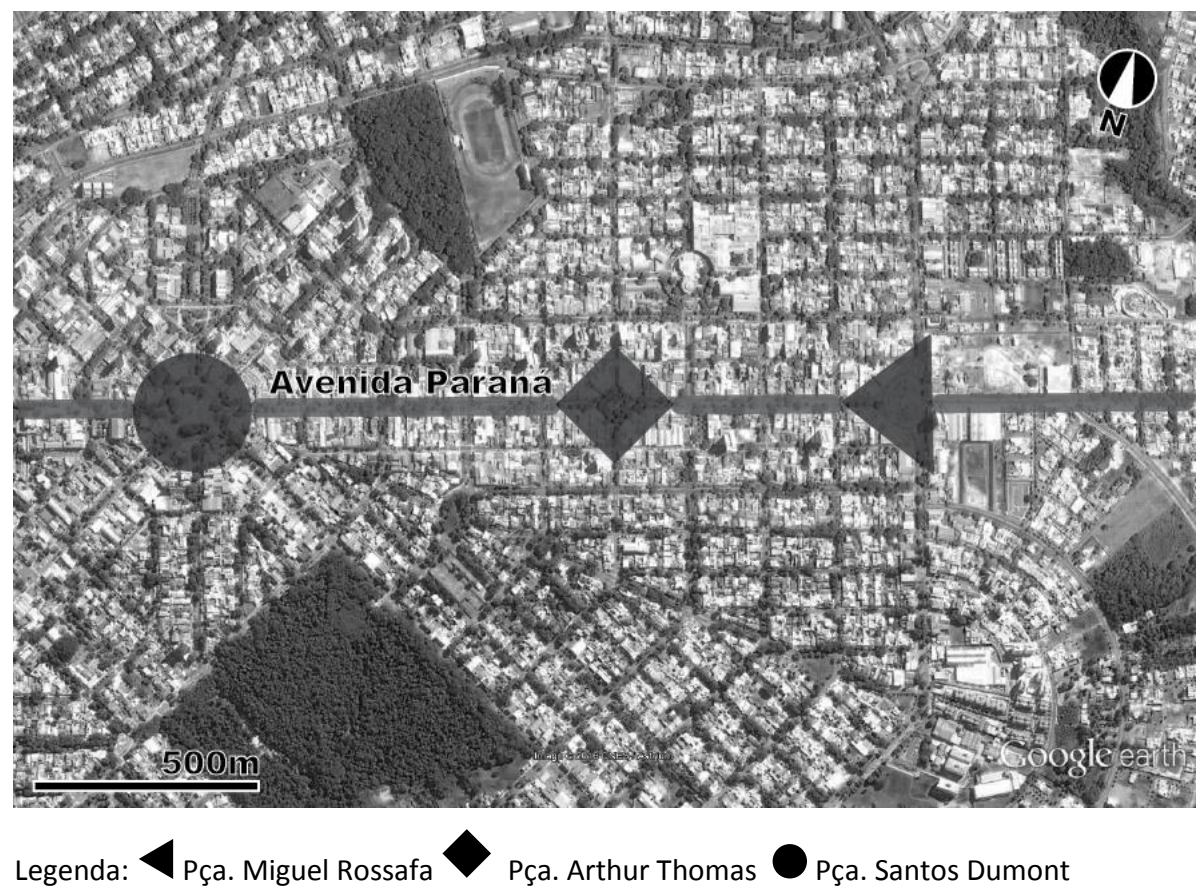

Fonte: Google Earth (2004), modificado pelos autores

A análise do caráter das praças oferece diretrizes para a requalificação dos aspectos negativos dos espaços livres. Neste capítulo, serão apresentados os objetos de estudo - praças Santos Dumont, Arthur Thomas e Miguel Rossafa - e os resultados obtidos com a aplicação da metodologia.

\subsection{Praça Santos Dumont}

A Praça Santos Dumont é a maior praça da cidade, apresenta-se como uma rotatória ${ }^{1}$ e um nó articulador de vias, conectando bairros residenciais ao centro da cidade. Seu projeto, datado de 1970, é de autoria do arquiteto modernista ícaro de Castro Mello. O entorno da praça apresenta uma concentração de edifícios bancários, o que a torna conhecida por "praça dos bancos". Essa característica foi intencionada pela Companhia Melhoramentos Norte do Paraná (CMNP), que estabeleceu a ocupação desta região (HULSMEYER et al., 2011).

No início da ocupação da cidade, a praça foi palco de acontecimentos culturais, políticos e cívicos. Hoje, a utilização da praça não se dá com a mesma intensidade das décadas passadas.

\section{Primeira Impressão}

\footnotetext{
${ }^{1}$ Rotatória é uma área livre de forma circular originalmente concebida como um organizador do fluxo de veículos. Com o passar do tempo, foi apropriada como praça a partir da incorporação de atividades em seu programa.
} 
O projeto da Praça Santos Dumont é de estilo moderno. Suas estruturas incluem um pátio central com um obelisco, salas comerciais - onde funcionava a biblioteca municipal - e um pequeno palco para apresentações. A inexistência de equipamentos de lazer ou esportivos e a dificuldade de acesso a torna pouco convidativa para o uso.

\section{Relevo}

O deslocamento dos usuários na praça é dificultado pelo seu relevo acentuado. A diferença de nível na praça chega a quase 10 metros.

\section{Acessos e circulação interna}

A Praça Santos Dumont é classificada como praça rotatória e consiste num dos pontos de tráfego mais intensos da cidade. Assim, o acesso à praça se torna difícil e perigoso, mesmo que existam faixas elevadas para pedestres em seu entorno.

\section{Vegetação}

O paisagismo está disposto em canteiros com espécies arbóreas, arbustivas e herbáceas. Apesar da variedade de espécies conferir maior dinamismo à praça, a vegetação necessita de manutenção.

\section{Mobiliário}

Os bancos são contínuos, em concreto, e não apresentam encosto. As lixeiras são de modelos pré-fabricados e distribuídos em toda a cidade. A iluminação consiste em luminárias altas em metal. Não existem elementos destinados ao lazer.

\section{Vistas}

O traçado urbano permite a visualização da Praça Santos Dumont em diversos pontos da cidade, uma vez que oito avenidas direcionam o fluxo até ela. Assim, é possível criar vistas panorâmicas mesmo a certa distância.

\section{Escala}

Essa escala da praça, por ser a maior da cidade, Ihe confere uma característica de monumentalidade.

\section{História e Significado da Praça}

Devido à sua importância histórica, social e política, a Praça Santos Dumont é a praça mais lembrada na cidade (HULSMEYER, 2004).

\section{História e Significado Visual do Entorno}

Seu entorno composto por edifícios bancários confere identidade e significação à Praça Santos Dumont. 


\section{Apropriação pela Comunidade}

A praça é pouco utilizada pelos citadinos cotidianamente, devido principalmente à dificuldade de acesso à ela. Em épocas festivas, em especial no Natal e Ano Novo, a prefeitura promove atividades no local, que incluem a presença de lanchonetes e de brincadeiras para o público infantil. Apenas nestas circunstancias, quando o tráfego de veículos do entorno da praça é controlado pela guarda municipal, esta recebe um número significativamente maior de usuários.

\subsection{Praça Arthur Thomas}

A Praça Arthur Thomas representa o marco zero da urbanização (HELD SILVA et al., 2013), sendo utilizada intensamente, como centro comercial regional, troca cultural e festividades, desde o início da década de 1960 (HELD SILVA, 2009). Sua ocupação teve início mesmo sem um projeto arquitetônico e paisagístico evidente. A praça passou por uma reforma, finalizada no segundo semestre de 2016, que alterou significativamente a composição do espaço livre. A reforma da praça apresenta alterações que incluem a troca do piso e do desenho dos caminhos, do paisagismo e a construção de quiosques que incorporarão à praça o lazer aquisitivo.

\section{Primeira Impressão}

Com a recente requalificação, a praça é percebida de forma positiva, devido à simplicidade das formas das estruturas e ao estado de conservação dos elementos.

\section{Relevo}

A topografia da praça apresenta desníveis suaves, com máximo de 1,30 metros, que são transpostos por meio de escadas e rampas.

\section{Acessos e circulação interna}

A praça está situada no centro da cidade, com diversos estabelecimentos comerciais próximos e se comporta como um ponto de conexão entre as centralidades das praças Santos Dumont e Miguel Rossafa. Devido a isso, o tráfego intenso de veículos ao redor da praça dificulta o acesso a ela. Não existem mecanismos que visam facilitar o acesso, como faixas de pedestres elevada ou redutores de velocidade. A circulação interna é facilitada devido ao desenho da praça apresentar uma espécie de pátio interno.

\section{Vegetação}

A vegetação é composta por canteiros gramados com maciços lineares de herbáceas e espécies arbóreas. As árvores da espécie Poincianella pluviosa (DC.) L.P.Queiroz (Sibipiruna) foram mantidas na revitalização e estão bem desenvolvidas, criando áreas de sombra no perímetro da praça. O pátio interno não apresenta indivíduos arbóreos, portanto, recebe luz solar direta. 


\section{Mobiliário}

Os bancos são feitos em concreto com encosto de madeira. As lixeiras apresentam um modelo idêntico ao distribuído nas ruas da cidade. A iluminação consiste em luminárias baixas com estilo republicano, do mesmo modelo distribuído nas ruas da cidade.

\section{Vistas}

A densidade de edificações no entorno, a vegetação perimetral e as ruas estreitas oferecem a sensação de um ambiente fechado e impede a vista da praça a partir de pontos mais distantes. Contudo, o pátio interno, livre de espécies arbóreas, oferece uma visão ampla do espaço livre, e árvores perimetrais funcionam como um "pano de fundo", transformando-o em uma espécie de clareira, que confere ao espaço uma característica acolhedora.

\section{Escala}

Apesar de esta ser uma das menores praças do traçado urbano, sua escala está adequada às atividades oferecidas.

\section{História e Significado da Praça}

A Praça Arthur Thomas marca o ponto de início da urbanização, a partir da abertura da mata (HELD SILVA et al., 2013). Assim, o seu significado está intimamente associado à fundação da cidade.

\section{História e Significado Visual do Entorno}

O papel social da Praça Arthur Thomas está relacionado ao edifício do seu entorno que abrigava o Bar Carioca. Os primeiros comércios da cidade foram implantados ao redor da praça. Assim, ainda que atualmente estes estabelecimentos sejam inexistentes, as edificações carregam significado histórico.

\section{Apropriação pela Comunidade}

A revitalização da praça levou um ano e meio para ser construída, enquanto isso, os usuários ficaram impossibilitados de utilizá-la. Com a recente reinauguração, aos poucos o espaço livre retoma a quantidade de usuários que recebia. Enquanto apenas um dos quiosques está aberto, onde funciona uma lanchonete, a praça é utilizada principalmente para o descanso ou como local de passagem.

\subsection{Praça Miguel Rossafa}

No projeto original da cidade, a Praça Miguel Rossafa se situava próxima do perímetro urbano e afastada do centro da cidade. A Praça Miguel Rossafa, inicialmente, não apresentava nenhum equipamento que incentivasse o uso do espaço livre. Na década de 2000, a praça recebeu uma intervenção em sua estrutura, porém permaneceu sem equipamentos de lazer 
ou culturais. Somente a partir de 2011 equipamentos foram gradualmente incorporados à praça, que atualmente apresenta como principais atividades o lazer infantil e esportivo.

\section{Primeira Impressão}

O projeto arquitetônico da Praça Miguel Rossafa é simples e suas atividades estão delimitadas, de forma que o ambiente é facilmente percebido pelo usuário. A praça oferece atividades principalmente de lazer, e esporadicamente abriga feiras temáticas. As condições de conservação da praça são satisfatórias, ainda que alguns de seus elementos necessitem de manutenção, como a academia da terceira idade (ATI).

\section{Relevo}

O relevo da praça é plano, sem desníveis, o que facilita o deslocamento dos usuários. O espaço livre está situado numa das cotas de nível mais altas da topografia da cidade.

\section{Acessos e circulação interna}

Devido à morfologia da praça pertencer ao tipo conhecido como praça rotatória, que estrutura a direciona a circulação viária, o acesso a ela é dificultado pela presença dos veículos. Existem faixas elevadas para pedestres que auxiliam o acesso, entretanto, o tráfego costuma ser intenso, pois a praça representa um ponto de conexão entre o centro da cidade e os bairros residenciais. Já a circulação interna da praça é fluida.

\section{Vegetação}

A vegetação da praça é composta por espécies arbóreas, áreas gramadas e alguns canteiros lineares com herbáceas. Apesar da variedade de espécies, principalmente arbóreas, o paisagismo apresenta um desenho aleatório.

\section{Mobiliário}

Os bancos são contínuos, sem encosto e feitos em concreto, estruturando o traçado da praça. As lixeiras, assim como nas outras praças analisadas, são iguais às implantadas em qualquer parte da cidade. A iluminação consiste em luminárias baixas de design moderno com lâmpadas de LED, o que oferece à praça uma característica moderna.

\section{Vistas}

O traçado da praça e as espécies vegetais escolhidas oferecem uma boa permeabilidade visual do espaço livre. Como citado no item relevo, a praça está situada em uma parte elevada da topografia, o que possibilita a criação de planos visuais panorâmicos da cidade.

\section{Escala}

A Praça Miguel Rossafa, após a alteração de sua tipologia em 2004, se transformou em uma das maiores praças da cidade. Sua área permitiu a implantação de elementos para diversas atividades. 


\section{História e Significado da Praça}

Ainda que a cidade de Umuarama apresente pouca idade, a Praça Miguel Rossafa está presente desde a sua fundação e foi palco de eventos cívicos marcantes da história da cidade.

\section{História e Significado Visual do Entorno}

Como citado no capítulo 4, o entorno da Praça Miguel Rossafa teve seu desenvolvimento impulsionado a partir da década de 1990. Assim, as edificações do entorno não apresentam nenhuma carga simbólica para a cidade.

\section{Apropriação pela Comunidade}

A praça é utilizada de frequentemente pelos citadinos, especialmente no período noturno, quando o clima está mais fresco, e em finais de semana. As atividades realizadas incluem a prática de exercícios físicos, como a caminhada e a ATI, o lazer infantil e o descanso.

\subsection{Síntese e gráfico radar}

A partir da pontuação atribuída aos critérios de cada uma das praças (Tabela 1), foi possível desenvolver um gráfico radar (Figura 2), onde os resultados podem ser avaliados mais facilmente. O gráfico mostra que, no geral, as três praças analisadas são percebidas positivamente. Enquanto as praças Arthur Thomas e Miguel Rossafa não receberam nenhuma pontuação negativa, a Praça Santos Dumont recebeu a nota 1 em cinco critérios (primeiras impressões; relevo; acessos e circulação interna; mobiliário e apropriação pela comunidade).

\begin{tabular}{|c|c|c|c|c|c|c|c|c|c|c|c|c|}
\hline Praça & & 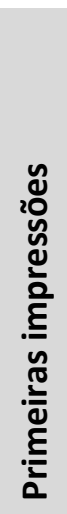 & 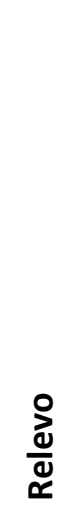 & 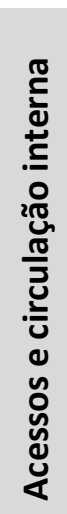 & 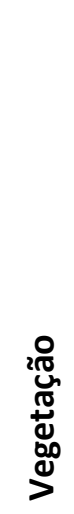 & 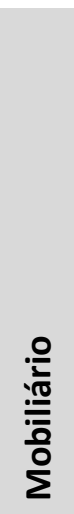 & 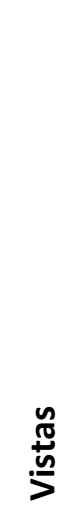 & 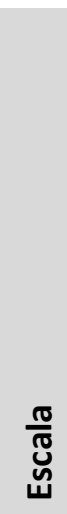 & 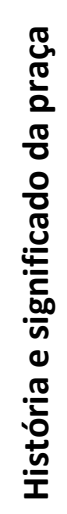 & 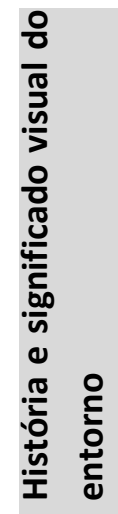 & 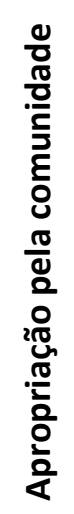 & $\frac{1}{5}$ \\
\hline $\begin{array}{l}\text { Santos } \\
\text { Dumont }\end{array}$ & & 1 & 1 & 1 & 2 & 1 & 3 & 3 & 3 & 3 & 1 & 19 \\
\hline $\begin{array}{l}\text { Arthur } \\
\text { Thomas }\end{array}$ & & 3 & 2 & 2 & 2 & 3 & 3 & 3 & 3 & 2 & 2 & 25 \\
\hline $\begin{array}{l}\text { Miguel } \\
\text { Rossafa }\end{array}$ & & 3 & 3 & 2 & 2 & 3 & 3 & 3 & 2 & 2 & 3 & 26 \\
\hline
\end{tabular}


Figura 2: Gráfico radar com a síntese dos resultados

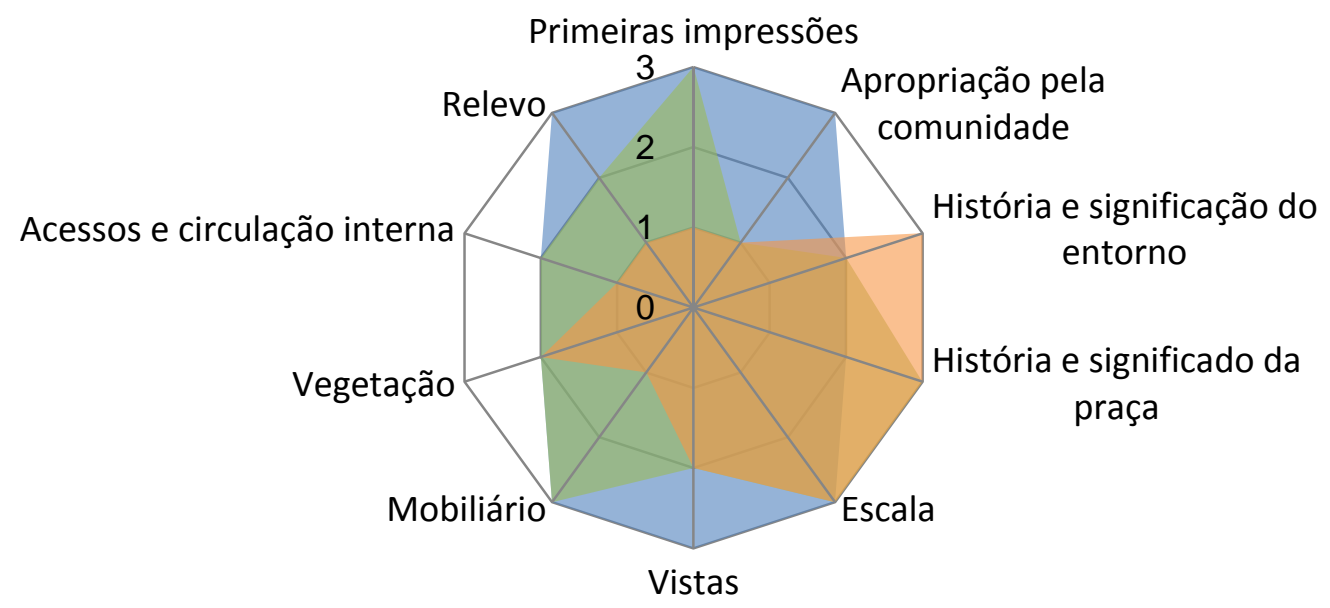

Legenda: Praça Santos Dumont Praça Arthur Thomas Praça Miguel Rossafa

Fonte: elaborado pelos autores

Os critérios estabelecidos pelo método podem ser classificados em três grupos. O primeiro compreende os aspectos que podem ser alterados e melhorados perante o planejamento e a intervenção urbana, sendo eles os acessos, a vegetação, o mobiliário e, consequentemente, as primeiras impressões. Outro grupo envolve o desenvolvimento social e cultural que naturalmente acomete a cidade, compreendido pelos aspectos da história da praça e do entorno e a apropriação pela comunidade. Por fim, um terceiro grupo identifica os aspectos que, apesar de ser possível a sua modificação, esta seria inviável ou dificultosa, sendo eles os aspectos do relevo, das vistas e da escala.

\section{CONCLUSÃO}

O planejamento urbano atua como mediador da qualidade ambiental das cidades, elevando, consequentemente, a qualidade de vida urbana. A análise das três praças em Umuarama permitiu a compreensão da importância destes locais na formação das cidades, e também a relevância da constante intervenção por parte do poder público.

Assim, conclui-se que a Praça Santos Dumont, que recebeu a menor pontuação, necessita de melhorias em seus aspectos físicos, uma vez que não passou por nenhuma reforma ao longo dos últimos anos. Já as praças Arthur Thomas e Miguel Rossafa, ambas com pontuações muito próximas, indicam que a revitalização constante contribui para a apreciação dos espaços públicos. Ainda, a Praça Miguel Rossafa recebeu a maior pontuação, o que indica que, mesmo que este espaço livre tenha sido menos representativo em termos históricos, ou que sua significação tenha sido agregada mais recentemente às outras praças, isto não influenciou negativamente a sua pontuação, uma vez que a praça recebe pequenas reformas constantemente. 
Desta forma, o projeto paisagístico se torna o principal instrumento da intervenção urbana. Os resultados desta pesquisa, obtidos por meio do método de avaliação do caráter, mostram que a constante requalificação da praça, desde pequenas reformas às grandes intervenções, contribui para a percepção positiva do espaço livre. Ainda, a falta de significação histórica, ou a sua existência em níveis mais brandos, não prejudica a percepção geral do espaço livre.

\section{AGRADECIMENTOS}

Agradecemos a CAPES (Coordenação de Aperfeiçoamento de Pessoal de Nível Superior) pelo apoio financeiro.

\section{REFERÊNCIAS}

BAKER, Elizabeth Audrey; SCHOOTMAN, Mario; KELLY, Cheryl; and BARNIDGE, Ellen. Do Recreational Resources Contribute to Physical Activity? Journal of Physical Activity and Health, v.5, p. 252-261, 2008. http://dx.doi.org/10.1123/ipah.5.2.252.

BARGOS, Danúbia Caporusso; MATIAS, Lindon Fonseca. Áreas Verdes Urbanas: Um Estudo de Revisão e Proposta Conceitual. REVSBAU, Soc. Bras. de Arborização Urbana. Piracicaba/SP, v.6, n.3, p. 172-188, 2011.

BARNETT, Jonathan. The Way We Were, the Way We Are: The Theory and Practice of Designing Cities since 1956. Harvard Design Magazine. Cambridge, n. 24, 2006.

BARTON, Jo; PRETTY, Jules. What is the Best Dose of Nature and Green Exercise for Improving Mental Health? A Multi-Study Analysis. Environmental Science \& Technology, [s.l.], v. 44, n. 10, p.3947-3955, 15 maio 2010. American Chemical Society (ACS). http://dx.doi.org/10.1021/es903183r.

BEDIMO-RUNG, Ariane L.; MOWEN, Andrew J.; COHEN, Deborah A. The significance of parks to physical activity and public health: a conceptual model. American Journal of Preventive Medicine. v. 28 (2 suppl 2) p.159-168, 2005. http://dx.doi.org/10.1016/j.amepre.2004.10.024.

CALDEIRA, Junia Marques. A Praça Brasileira: trajetória de espaço urbano - origem e modernidade. 432 f. Tese (Doutorado em História) - Universidade Estadual de Campinas, Campinas (São Paulo), 2007.

A praça colonial brasileira. Univ. Arquitetura e Comunic. Social. Brasília, v. 7, n. 1, p. 19-39, jan./jun. 2010.

COSTA, Renata Geniany Silva; COLESANTI, Marlene Muno. A Contribuição da Percepção Ambiental Nos Estudos das Áreas Verdes. Ra'e Ga, Curitiba, v. 22, p.238-251, 26 jun. 2011. Universidade Federal do Paraná. http://dx.doi.org/10.5380/raega.v22i0.21774.

FISHER, K. John; LI, Fuzhong; MICHAEL, Yvonne; CLEVELAND, Minot. Neighborhood-level influences on physical activity among older adults: a multilevel analysis. Journal of Aging and Physical Activity, v. 11, p. 45-63, 2004.

GOMES, Marcos Antônio Silvestre. De Largo A Jardim: Praças Públicas No Brasil - Algumas aproximações. Estudos Geográficos, Rio Claro, n. 5, p. 101-120, 2007. 
HARTIG, Terry; EVANS, Gary W.; JAMNER, Larry D.; DAVIS, Deborah S.; GÄRLING, Toomy. Tracking restoration in natural and urban field settings. Journal of Environmental Psychology, 2003, 23, 109-23. http://dx.doi.org/10.1016/S0272-4944(02)00109-3.

HARTIG, Terry; MANG, Marlis; EVANS, Gary W. Restorative effects of natural environment experiences. Environment and Behavior, v. 23, n. 1, p. 3-26, 1991. DOI: 10.1177/0013916591231001.

HELD SILVA, Regina de. A Praça - Identidade e Apropriação Pública Avaliação Pós-Ocupação da Praça Arthur Thomas no Município de Umuarama - Paraná. 231 f. Dissertação (Mestrado em Engenharia Urbana) - Universidade Estadual de Maringá, Maringá, 2009.

; ANGELIS, Bruno Luiz Domingos De; CASTRO, Paulo Henrique Marques de; FERREIRA, Yoshiya Nakagawara; APOLINÁRIO, Eduardo Ferreira; PICOLLO, Camila Gisele. Entre o encontro e o deslocamento, no 'devir-urbe'. In: Encuentro de Geógrafos de América Latinados: Reencontro de Saberes Territoriales Latinoamericanos, 2013, Lima. Anales do XIV EGAL. Lima, 2013.

HULSMEYER, Alexander Fabbri. Qualidade do Espaço Livre Urbano: Valores ambientais, culturais e funcionais. 234 f. Dissertação (Mestrado em em Geografia Meio Ambiente e Desenvolvimento) -Universidade Estadual de Londrina, Londrina, 2004.

.; HELD SILVA, Regina de; PURIFICAÇÃO, Caroline Salgueiro da; BARRETO, Maria Izabel de Melo; RODRIGUES, Rodrigo. A paisagem urbana como herança cultural: A praça Santos Dumont, Umuarama, Estado do Paraná, Brasil. Acta Scientiarum. Technology. Maringá, v. 33, n. 2, p. 113-121, 2011.

. A Cidade Através dos Seus Sistemas de Espaços Livres: Estrutura e configuração da paisagem urbana - Um estudo de caso em Umuarama - PR. $310 \mathrm{f}$. Tese (Doutorado em Arquitetura e Urbanismo) - Universidade de São Paulo, São Paulo, 2014.

IBGE - Instituto Brasileiro de Geografia e Estatística. Infográficos: dados gerais do município. Umuarama - Paraná. Disponível em: <http://cod.ibge.gov.br/BFE>. Acesso em: 03 abr. 2015.

KAWACHI, Ichiro; KENNEDY, Bruce P.; LOCHNER, Kimberly; PROTHROW-SMITH, Deborah. Social capital, income inequality and mortality. American Journal of Public Health, v. 87, p. 1491-1498, 1997.

KRIER, Rob. Urban Space. London: Academy Editions, 1979.

KUO, Frances E.; SULLIVAN, William C.; COLEY, Rebekah Levine; BRUNSON, Liesette. Fertile ground for community: inner-city neighbourhood common spaces. American Journal of Community Psychology, v. 26, n. 6, p. 823-51, 1998.

MAAS, Jolanda; VERHEIJ, Robert A.; GROENEWEGEN, Peter P.; DE VRIES, Sjerp; SPREEUWENBERG, Peter. Green space, urbanity, and health: how strong is the relation. J. Epidemiol. Community Health, v. 60, p. 587-92, 2006. DOI: 10.1136/jech.2005.043125.

MARX, Murillo. Nosso chão: Do Sagrado ao Profano. São Paulo: Editora da Universidade de São Paulo, 1989. 219 p.

$\mathrm{NUCCl}$, João Carlos. Qualidade ambiental e adensamento urbano: um estudo de ecologia e planejamento da paisagem aplicado ao distrito de Santa Cecília (MSP). 2ª ed. Curitiba: O Autor, 2008. $150 \mathrm{p}$. 
OTTONI, Dacio Araújo Benedicto. Cidade-Jardim: Formação e percurso de uma ideia. In: HOWARD, Ebenezer. Cidades-Jardins de Amanhã. 2 ed. São Paulo: Hucitec, 1996, p. 10-101.

PRETTY, Jules; PEACOCK, Jo; SELLENS, Martin; GRIFFIN, Murray. The mental and physical health outcomes of green exercise. International Journal of Environmental Health Research, 2005, 15 (5), 319-37. DOI: 10.1080/09603120500155963.

ROBBA, Fábio; MACEDO, Silvio Soares. Praças Brasileiras = Public Squares in Brazil. 3 ed. (1 ed - 2002). Edusp - Editora da Universidade de São Paulo: São Paulo, 2010. [Coleção Quapá].

SITTE, Camillo. A Construção de Cidades Segundo Princípios Artísticos. Trad. Ricardo Ferreira Henrique. São Paulo: Ática, 1992.

SZEREMETA, Bani; ZANNIN, Paulo Henrique Trombetta. A Importância dos Parques Urbanos e Áreas Verdes na Promoção da Qualidade de Vida em Cidades. Ra'e Ga, Curitiba, v. 29, p.177193, 6 dez. 2013. Universidade Federal do Parana. http://dx.doi.org/10.5380/raega.v29i0.30747.

UMUARAMA. Lei Ordinária no 2275, de 04 de maio de 2000. Autoriza o Poder Executivo a readequar a Praça Miguel Rossafa.

WELLS, Nancy M.; ASHDOWN, Susan P.; DAVIES, Elizabeth H. S.; COWETT, Fred D.; YANG, Yizhao. Environment, design and obesity. Environment and Behaior, v. 39, n. 1, p. 6-33, 2007. DOI: $10.1177 / 0013916506295570$.

YAMAKI, Humberto. Praças Históricas: Avaliação do Caráter. Londrina: Edições Humanidades, 2008. 